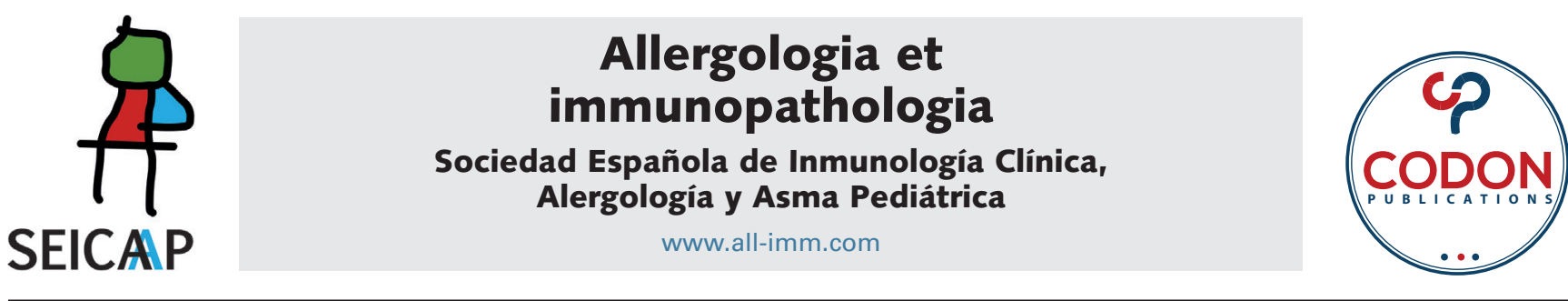

\title{
Three-year pollen and fungi calendar in a Mediterranean region of the Northeast Greece
}

\author{
Petros Katsimpris ${ }^{a *}$, Christos Nikolaidis ${ }^{a}$, Theodora-Eleftheria Deftereou ${ }^{b}$, \\ Dimitrios Balatsouras ${ }^{c}$, Athanasia Printzad, Theodoros lliou ${ }^{a}$, Triantafyllos Alexiadis ${ }^{b}$, \\ Ipek Chatzisouleiman ${ }^{\mathrm{a}}$, Marianna Samara ${ }^{\mathrm{a}}$, Jannis Constantinidis ${ }^{\mathrm{d}}$, Maria Lambropoulou ${ }^{\mathrm{b}}$, \\ Michael Katotomichelakis ${ }^{a}$
}

${ }^{a}$ Department of Otorhinolaryngology, Medical School, Democritus University of Thrace, Alexandroupolis, Greece ${ }^{b}$ Laboratory of Histology-Embryology, Medical School, Democritus University of Thrace, Alexandroupolis, Greece 'Department of Otorhinolaryngology, "Tzanion" General Hospital, Pireaus, Greece ${ }^{d}$ Department of Otorhinolaryngology, Medical School, Faculty of Health Sciences, Aristotle University of Thessaloniki, Thessaloniki, Greece

Received 17 August 2021; Accepted 9 November 2021

Available online 1 March 2022

\section{KEYWORDS}

allergic disease;

Mediterranean;

pollen calendar;

pollens and fungi;

seasonal trends

\begin{abstract}
Introduction and objectives: Pollen calendars have been proved clinically important in allergic disease management, as differences in airborne allergens exist not only between different countries but also between regions of the same country as well. This study aims to provide new data regarding the atmospheric pollen and fungi content of a Mediterranean region (Western Thrace/North-East Greece) and discuss seasonal trends, differences in pollen grains and fungi spores' circulation over the years, and correlations with climate parameters.

Material and methods: A 7-day continuously running volumetric trap was used to collect circulating pollen grains and fungi spores. Pollen taxa and fungi were characterized by standard protocols and counted as grains $/ \mathrm{m}^{3}$ and average total grains and spores. The primary allergenic pollen season was discovered, and their 10-day averages were measured over time. Correlations with temperature, rain, and humidity were assessed by single linear regression analysis.

Results: Pollen grains from nine pollen families were identified, including five arboreal, two nonarboreal taxa, and spores from two fungi species. The three most prevalent taxa were Oleaceae, Poaceae, Pinaceae, and Cladosporium in the fungi. Peak pollen concentrations were detected during April and May, with daily averages exceeding 170 grains $/ \mathrm{m}^{3}$. Poaceae presented the longest pollen season of 342 days and Oleaceae the shortest, extending to only
\end{abstract}

*Corresponding author: Professor Assoc. Dr. Michael Katotomichelakis, MD, MSc, PhD, Head of the Department of OtoRhinoLaryngology, Alexandroupolis University Hospital, Alexandroupolis, 68100 Greece. Email address: mkatotom@med.duth.gr 
110 days, during the 3years. Cladosporium was the fungus with the highest spore concentration $(180,129.9$ spores) compared with Alternaria $(28,026.1$ spores). Correlations with meteorological parameters showed variable associations among different taxa, with rainfall and relative humidity being the most significant determinants.

Conclusion: In this study, the pollenic and fungal spectrum of a Mediterranean region and information that can be proved clinically significant for the appropriate diagnostic and therapeutic approach of allergic patients was presented.

(C) 2022 Codon Publications. Published by Codon Publications.

\section{Introduction}

Pollen allergy represents a hypersensitivity reaction of the respiratory system. ${ }^{1}$ An allergic reaction occurs when sensitized individuals inhale airborne allergens, such as typically tree, grass, weed pollens, and some fungi. ${ }^{2,3}$ Recent studies show that the severity of allergic symptoms depends on the density of aeroallergen circulation and the duration of exposure..$^{4-7}$ Accordingly, accurate descriptions of pollination and fungi start and end periods are critical for both patients and doctors. ${ }^{8-10}$ Since the number of people affected by pollen allergy in Europe has been increasing steadily in the last decades ${ }^{3}$ and taking into account that allergic rhinitis (AR) has a considerable socioeconomic cost, ${ }^{11-14}$ this information can lower the overall financial and social burden of this disease. Pollen and fungal allergy is a regionally variable disease driven by numerous environmental factors, including local flora, weather, climate, and air pollution. ${ }^{15-17}$ As a result, the allergenic content of the atmosphere varies not only among countries but even in the same country, depending on the climate (temperature, winds, rains, and humidity), geography, vegetation, and cultural factors. ${ }^{8,18,19}$ Pollen calendars have been constructed in many countries to keep track of the pollen variety and concentration of airborne pollens. Thus, the need to forecast and define future and current pollen seasons in a pollen calendar form for every region is pivotal to allergic disease epidemiology and early diagnosis and appropriate management of allergic diseases. More specifically, pollen maps can help allergic patients and doctors identify potential triggers, decide appropriate diagnostic testing, and apply for precision medicine. ${ }^{10}$ They can also help the public health system to develop early warning systems, improve guidance to limit exposure, and promote therapy in advance of high pollen season loads. ${ }^{1}$

Although previous reported data for various areas in Greece showed interesting variability, there is no recent data. ${ }^{20-23}$ This is the first study to describe the atmospheric pollen and fungi content of a Mediterranean region during a 3-year (2015-2017) period from the only pollen station in Greece. Moreover, this study follows our original research of 2013 conducted in the same area of Western Thrace/ NE Greece; $2,10,24$ and discusses the differences in pollen and fungi circulation over the years. Hence, this study can add to the understanding of the overall development of the pollinic spectrum of the region, compiling all data collected since 2013.

\section{Methods}

The study was conducted in Alexandroupolis, a city located in North-Eastern Greece, at 40.51' N 25.52' E. Alexandroupolis has a typical Mediterranean climate (warm and temperate), with an average annual temperature of $15.0^{\circ} \mathrm{C}$, relative humidity of $67.4 \%$, and annual precipitation of $695 \mathrm{~mm}$. It is situated near the delta of the Evros river, $750 \mathrm{~km}$ North-East of Athens (Figure 1). Local vegetation includes evergreen, deciduous fruit trees (e.g., pines, cypresses, oaks, and olives), and a variety of other shrubs, grasses, and herbs (e.g., mugwort, laurel, mint, and thyme) that create a diverse palynological environment. For pollen capturing, a 7-day recording volumetric spore sampler (Burkard Scientific, Ltd., England, UK) was placed $21 \mathrm{~m}$ above the ground, on the roof of the University Hospital of Alexandroupolis, $6 \mathrm{~km}$ West of the city of Alexandroupolis, according to instructions provided by the manufacturer. The unit was operating continuously for 3 years (January 2015-December 2017), collecting 10 liters of air per minute. A strip of silicone-coated Melinex tape was exposed to the air for trapping the spores, was cut into $48 \mathrm{~mm}$ segments representing 24 hours periods, and was changed once a week. These segments were mounted on microscopic slides using Gelvatol mixed with a stain (acid fuchsin) to enable visualization under a high-resolution light microscope (400x magnification; Olympus BX40, Olympus, Tokyo, Japan).

Pollen grains and fungi spores were identified following standard manuals, ${ }^{25}$ counted according to the guidelines of the British Aerobiology Federation, ${ }^{26}$ and were expressed as number of grains and spores per cubic meter of air and total grains and spores. The seasonal distribution of pollen counts was presented as 10-day-running average. The main pollen season (MPS) was characterized as $90 \%$ of the seasonal pollen count, starting on the day when $5 \%$ of the total pollen had been detected, and ending on the day $95 \%$ of the total pollen had been measured. Aeroallergens counted are the most frequently implicated in AR, not only in the Mediterranean and European context, ${ }^{8,18-23,27-31}$ but also worldwide. ${ }^{32-34}$ They include grasses (family [f.] Poaceael Gramineae), trees (f. Oleaceae/olive, f. Cupressaceael cypress, f. Pinaceae/pine, f. Betulaceae/beech, oak, and f. Platanaceae/plane), and weeds (f. Chenopodiaceae/chenopodium). The pollen graph was constructed using a specific scale, each level corresponding to a particular amount of pollen grains. The levels included a total sum of pollen grains/spores per 10 days as follows: 1st level: 1-2; 2nd 


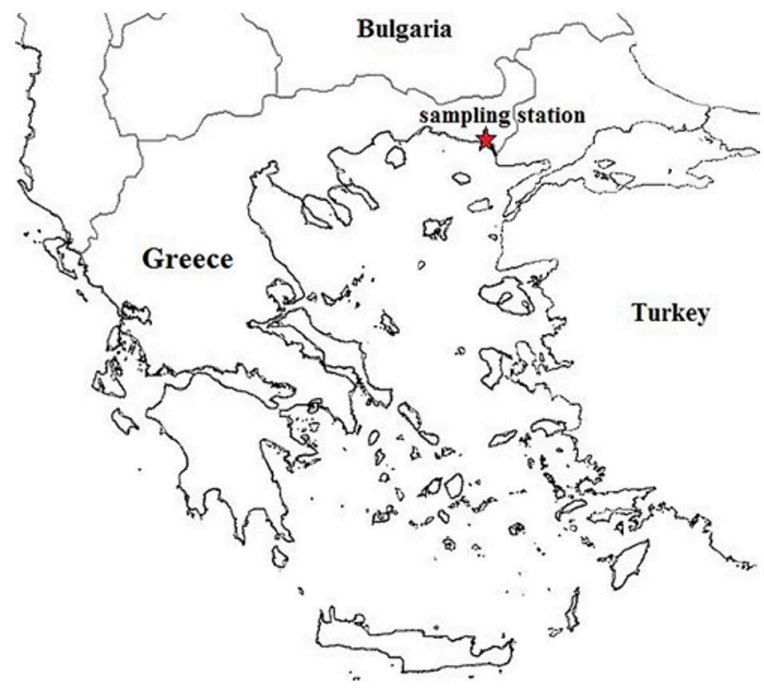

Figure 1 Map of the study region.

level: 3-5; 3rd level: 6-11; 4th level: 12-24; 5th level: 25-49; 6th level: 50-99; 7th level: 100-199; 8th level: 200-399; 9th level: 400-799; 10th level: 800-1599; and 11th level: a sum of more than 1600 pollen grains/fungi spores per 10 days. ${ }^{27}$ This way, all interactions between external factors and pollen and fungi concentrations were significantly reduced, enabling the comparison of different concentrations of pollen and fungi species throughout the calendar year. ${ }^{31}$

Meteorological data were obtained from the regional station of the Hellenic National Meteorological Service situated close to the sampling site (http://www.hnms.gr). Climate parameters such as daily mean temperature $\left({ }^{\circ} \mathrm{C}\right)$, relative humidity $(\%)$, and rainfall $(\mathrm{mm})$ were recorded. The correlation between individual meteorological parameters and pollen and fungi counts were assessed by regression analysis, using SPSS $15.0^{\circledR}$ software package (SPSS, Inc., Release Version 15.0, Chicago IL, USA). $\mathrm{P}<0.05$ was considered to be statistically significant.

\section{Results}

Airborne pollen grains belonging to nine families were counted, including a total of nine allergens. Briefly, this study included five arboreal taxa (Cupressaceae, Pinaceae, Platanaceae, Betulaceae, and Olaceaceae), two nonarboreal taxa (Poaceae and Chenopodiaceae) and two fungal spores (Alternaria and Cladosporium). Running means or moving averages for 10 days were used for smoothing the values to make the trend of seasonal variation more easily observed.

The start and the end date of the pollen grains count is demonstrated in Table 1, with the number of the pollination days and the peak days of each taxa. Pollen taxa were detected throughout the calendar year and peaked mainly during the spring months (March to May) with their average numbers for the 2015-2017 period (ranging from
366.8 to 9897.1 total grains) as depicted in Table 2. The predominant pollen type in the airborne spectrum was Oleaceae, with a total pollen number of 16033.7 grains $/ \mathrm{m}^{3}$ during 2015-2017. The highest concentration of Oleaceae pollen was noticed from mid-April to the end of May, with the peak date observed in May 2015-2016 and in April for 2017. Remarkably, the pollen season of Oleaceae was the shortest, with a total of 35 days. Oleaceae was followed by herbaceous plants (Poaceae) that represented the second category detected on high percentage with a total pollen number of 9445.1 grains $/ \mathrm{m}^{3}$ in the 3 years studied. Meanwhile, in Poaceae with the longest pollination period (125 days). The highest concentration was observed from early April to mid-July (the peak in April), except for 2015 wherein the pollination period was the longest with the peak at the beginning of July. For the rest of the arboreal species (Cupressaceae, Pinaceae, Plataneceae or Betulaceae), the pollination time was divided into three main periods: February-May (Cupressaceae and Betulaceae), February-June (Pinaceae), and March-June (Plataneceae). Pinaceae was the third most frequent species detected with a total number of grains $/ \mathrm{m}^{3}$ at 7334.8 , showing the longest pollination period (109 days) after Poaceae. The peak concentration was observed from the end of February to mid-June, with the highest in March-April. We counted a total number of 2188.6 grains $/ \mathrm{m}^{3}$ for Chenopodiaceae, presenting the longest pollination period (129 days) among all pollens studied. The highest concentration was observed during summer, with the peak in mid-August. All data recorded for all the above species are depicted in Table 1. Furthermore, fungal spores were recorded during all the months of the calendar years. Alternaria and Cladosporium outdoor molds were monitored throughout the calendar year (January to December), with their average numbers for the 2015-2017 period ranging from 27.3 to 41388.3 spores per month. The main spore season (MSS) for fungal circulation in the atmosphere of Western Thrace was observed from May to November. The highest concentration of Alternaria spp and Cladosporium spp was noticed in summer, with its peak in June for Alternaria spp., and in July for Cladosporium spp, with a second smaller peak concentration in the period of August-November for the latter. The highest average total amount of fungal spores for the whole 3-year period was observed for Cladosporium, with $180,129.9$ spores (total spores), and the sum for Alternaria was 28,061.1 total spores. The data of Alternaria and Cladosporium airborne distribution are presented in detail in Table 2. A graphical presentation of the concentrations of all pollens and fungi is depicted in Figure 2.

Among pollens, the major pollen producers were arboreal plants, namely Oleaceae (35.7\%), Pinaceae (16.3\%), Cupressaceae (14.5\%), Platanaceae (6.2\%), and Betulaceae (1.3\%), which accounted for $74.1 \%$ of the total pollen grains (Table 2). The family Oleaceae was dominated by Olea europaea (olives), followed by Fraxinus and Ligustrum species. Cupressaceae were associated with Cupressus or Juniperus spp., whereas Pinaceae included a mixture of Pinus, Abies, or Cedrus taxa. Among nonarboreal plants, pollen grains belonging to Poaceae (21\%) and Chenopodiaceae (4.9\%) dominated the atmosphere during the study period. Table 2 presents the monthly average distributions of all taxa. The 
Table 1 Characteristics of the main pollen seasons (2015-2017).

\begin{tabular}{|c|c|c|c|c|c|c|}
\hline Pollen type & $\begin{array}{c}\text { Start date } \\
(5 \%)\end{array}$ & $\begin{array}{l}\text { End date } \\
\qquad(95 \%)\end{array}$ & $\begin{array}{c}\text { Season } \\
\text { duration (days) }\end{array}$ & Peak date & $\begin{array}{c}\text { Peak concentration } \\
\left(\text { Grains } / \mathrm{m}^{3}\right)\end{array}$ & $\begin{array}{l}\text { Total pollen } \\
\left(\text { Grains } / \mathrm{m}^{3}\right)\end{array}$ \\
\hline \multicolumn{7}{|l|}{ Pollen season (2015) } \\
\hline Cupressaceae & February 03 & May 16 & 103 & March 07 & 126.9 & 1569.8 \\
\hline Pinaceae & February 26 & June 12 & 107 & April 25 & 123.1 & 2027.2 \\
\hline Platanaceae & March 29 & June 21 & 85 & May 08 & 38.9 & 713.3 \\
\hline Betulaceae & February 09 & May 19 & 100 & February 21 & 9.7 & 142.0 \\
\hline Oleaceae & April 27 & May 31 & 35 & May 30 & 486 & 5277.4 \\
\hline Poaceae & April 17 & July 19 & 125 & July 01 & 97.2 & 2219.9 \\
\hline Chenopodiaceae & June 10 & October 16 & 129 & August 13 & 20.0 & 697.7 \\
\hline \multicolumn{7}{|l|}{ Pollen season (2016) } \\
\hline Cupressaceae & February 07 & May 18 & 102 & March 06 & 69.1 & 2191.9 \\
\hline Pinaceae & February 28 & June 08 & 103 & March 04 & 133.9 & 2593.6 \\
\hline Platanaceae & March 12 & June 09 & 90 & May 18 & 121.5 & 1084.9 \\
\hline Betulaceae & February 16 & May 31 & 106 & March 01 & 18.9 & 217.6 \\
\hline Oleaceae & April 23 & May 29 & 37 & May 08 & 502.2 & 4664.0 \\
\hline Poaceae & April 04 & July 16 & 104 & April 23 & 237.6 & 3578.0 \\
\hline Chenopodiaceae & June 12 & September 19 & 100 & August 12 & 20.0 & 702.0 \\
\hline \multicolumn{7}{|l|}{ Pollen season (2017) } \\
\hline Cupressaceae & February 10 & May 19 & 99 & March 06 & 77.8 & 2770.7 \\
\hline Pinaceae & February 28 & June 16 & 109 & April 25 & 110.2 & 2714.0 \\
\hline Platanaceae & March 15 & June 14 & 92 & May 08 & 77.8 & 999.5 \\
\hline Betulaceae & February 15 & May 19 & 94 & March 08 & 20.5 & 235.4 \\
\hline Oleaceae & April 24 & May 31 & 38 & April 08 & 405.0 & 6092.3 \\
\hline Poaceae & April 03 & July 25 & 113 & April 22 & 334.8 & 3647.2 \\
\hline Chenopodiaceae & June 14 & September 09 & 88 & August 16 & 24.3 & 788.9 \\
\hline
\end{tabular}

Table 2 Total pollens averages (2015-2017), expressed in total pollen grains and fungi spores.

\begin{tabular}{lccccccccc}
\hline Averages & Cupressaceae & Pinaceae & Platanaceae & Betulaceae & Oleaceae & Poaceae & Chenopodiaceae & Alternaria & Cladosporium \\
\hline January & 154.3 & 0 & 0 & 1.3 & 0 & 1.6 & 0 & 27.3 & 1045.3 \\
February & 369.6 & 273 & 44 & 125 & 50 & 50 & 0 & 244.3 & 582.6 \\
March & 1660 & 1103.6 & 130.3 & 168.3 & 283.3 & 104 & 0 & 247 & 1714.3 \\
April & 994 & 1274.3 & 378 & 19.6 & 278.6 & 2126.3 & 2 & 446.3 & 5376.3 \\
May & 832.3 & 1471.6 & 1003.3 & 52 & 8978.3 & 1906.3 & 40 & 3934 & $12,051.6$ \\
June & 19.3 & 388.6 & 169 & 0 & 225 & 908.6 & 136.3 & 8964.3 & $39,905.6$ \\
July & 0 & 2 & 1 & 0 & 33.6 & 543.3 & 334.6 & 5088 & $41,388.3$ \\
August & 0 & 0 & 0 & 0 & 2 & 181.6 & 635 & 4177 & $33,428.6$ \\
September & 0.3 & 0 & 0 & 0 & 0 & 0 & 142 & 2104 & 20,542 \\
October & 0 & 0 & 0 & 0 & 0 & 0.6 & 60.3 & 1093.3 & 12,445 \\
November & 2.3 & 14.3 & 1.6 & 0.6 & 46.3 & 7.6 & 0.3 & 938.3 & 7643.3 \\
December & 0.3 & 0 & 0 & 0 & 0 & 0 & 0 & 762.3 & 4007 \\
Total & 4032.4 & 4527.4 & 1727.2 & 366.8 & 9897.1 & 5829.9 & 1350.5 & 28026.1 & $1,80129.9$ \\
\hline
\end{tabular}

highest concentrations of pollens were observed during spring with an average of 3449.5, 5072.8, and 14283.8 pollen grains per month respectively for March, April, and May, respectively. The highest concentrations of pollen counts (14283.8 grains) were counted in May and the lowest ( $<1$ grain) in December. Notably, Oleaceae had the shortest pollen season of just 35 days in 2015, although they presented the maximum pollen load in the atmosphere (9897.1 grain) during their seasonal circle in the 3 years (Table 2).

In the present study, the relationship of daily pollenand spore concentrations with three climatic parameters, namely the average daily temperature $\left({ }^{\circ} \mathrm{C}\right)$, relative humidity (\%), and rainfall $(\mathrm{mm})$, were examined (Table 3). Most correlations were very strong. The association between individual meteorological parameters and pollen and fungi concentration was assessed by single linear regression analysis. The results of significant associations $(\mathrm{P}<0.05)$ are given in Table 3. Among arboreal taxa, Cupressaceae were associated with rainfall $(P<0.001)$, and Betulaceae with rainfall $(\mathrm{P}=0.005)$ and relative humidity $(\mathrm{P}=0.03)$. Among nonarboreal taxa, Chenopodiaceae was associated with temperature $(P<0.001)$, relative humidity $(P<0.001)$, and rainfall $(P=0.023)$, whereas Poaceae did not show any association. Regarding the correlation of fungal 
(A)

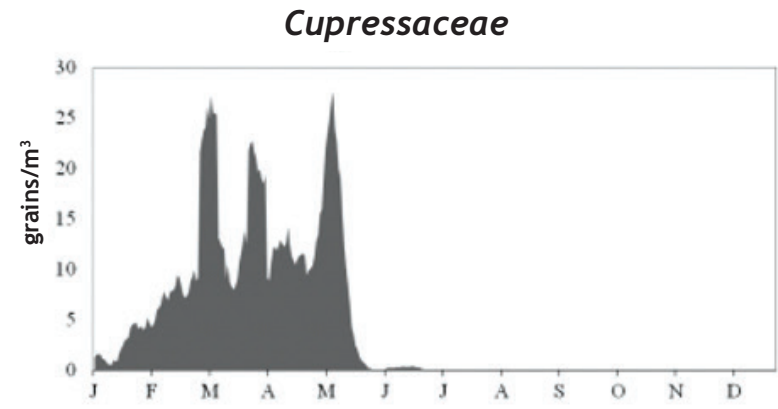

Platanaceae

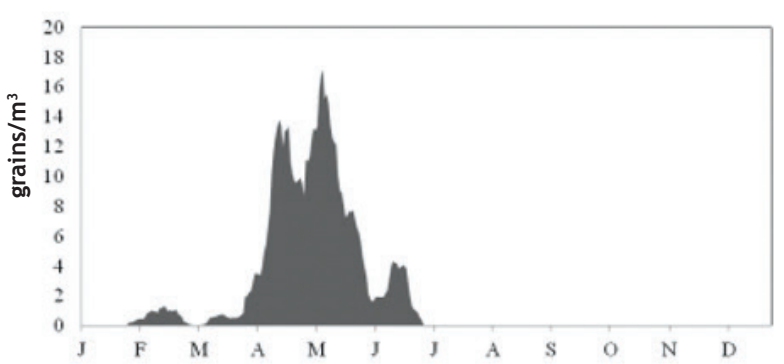

Oleaceae

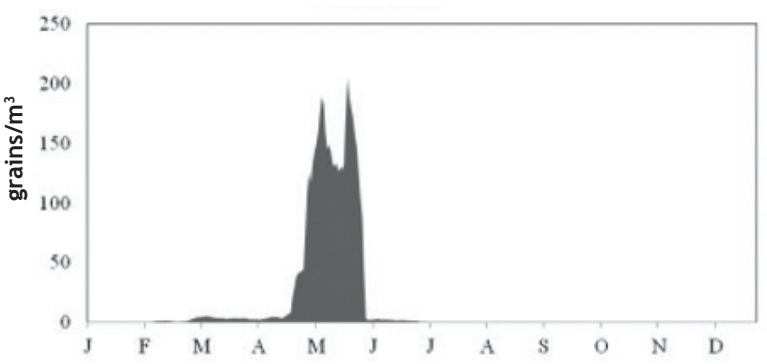

Pinaceae

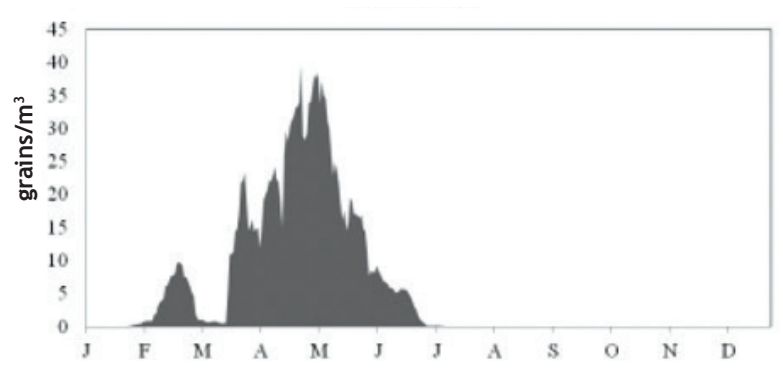

Betulaceae

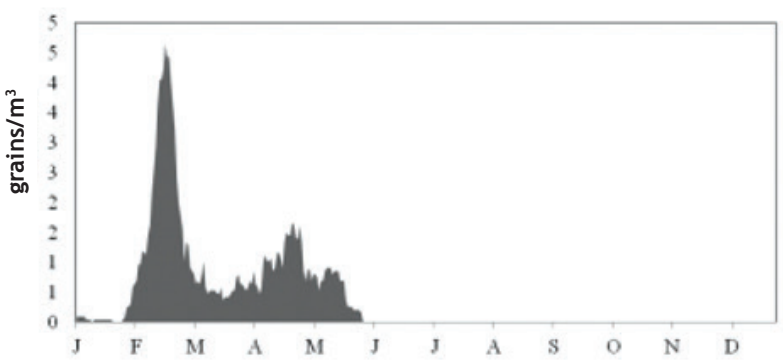

Poeaceae

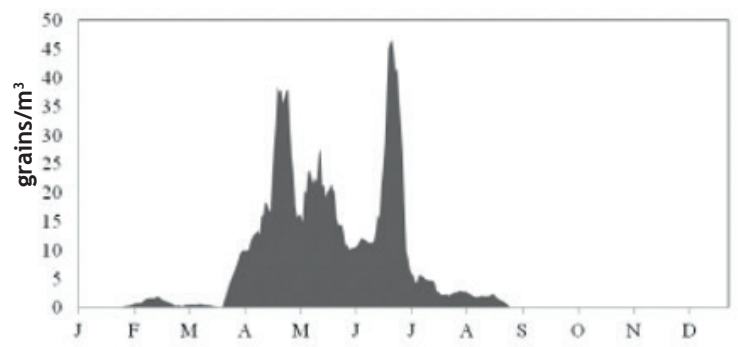

Chenopodiaceae
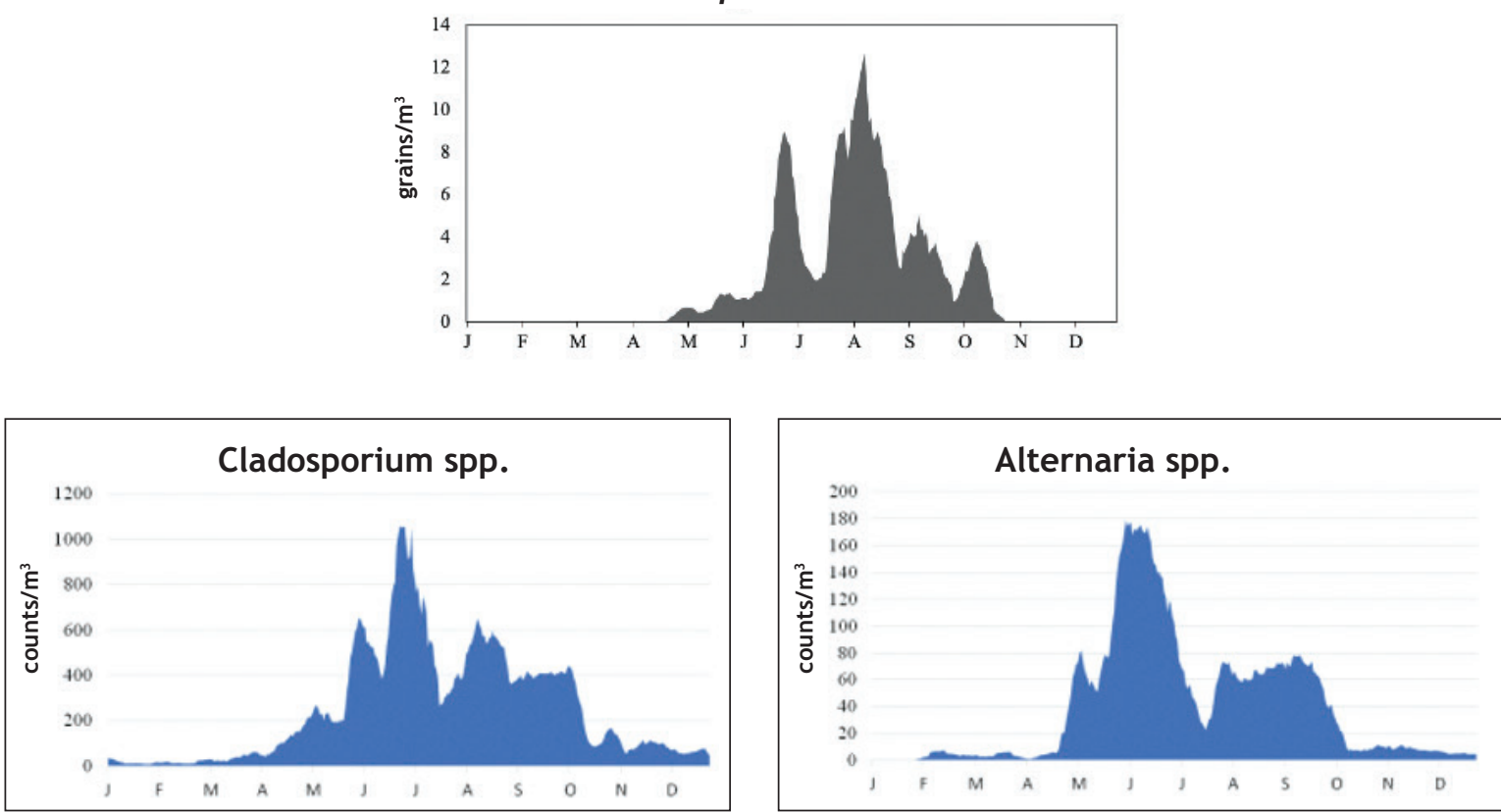

Figure 2 (A) Pollen and fungi concentrations (grains-spores $/ \mathrm{m}^{3}$ ) as 10-day running averages (2015 year), (B) Pollen and fungi concentrations (grains-spores $/ \mathrm{m}^{3}$ ) as 10-day running averages (2016 year), and (C) Pollen and fungi concentrations (grains-spores/ $\mathrm{m}^{3}$ ) as 10-day running averages (2017 year). 
(B)

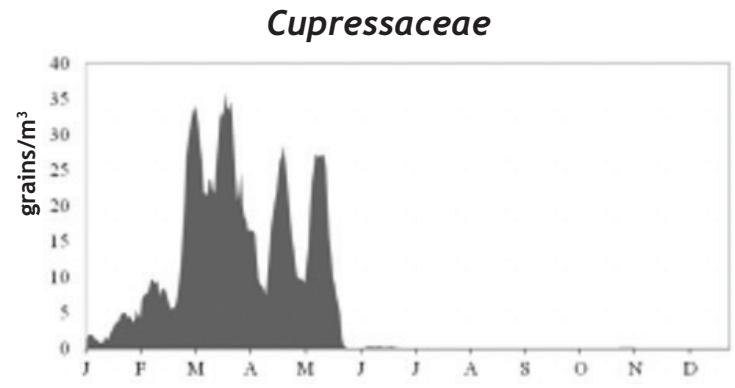

Platanaceae

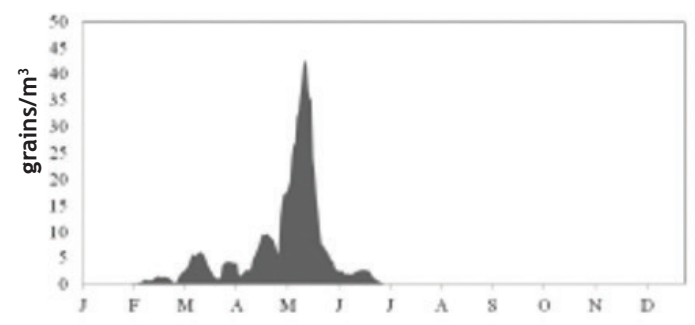

Oleaceae

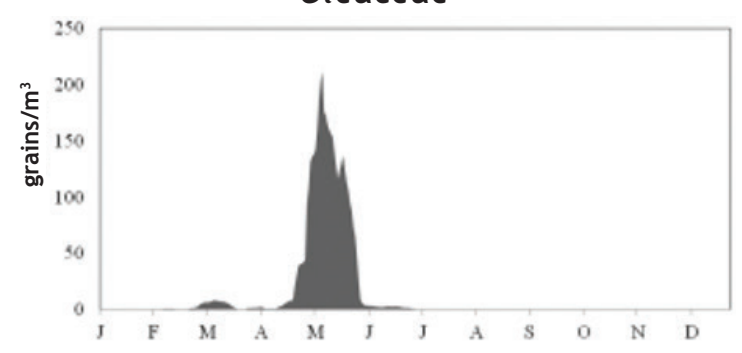

Pinaceae

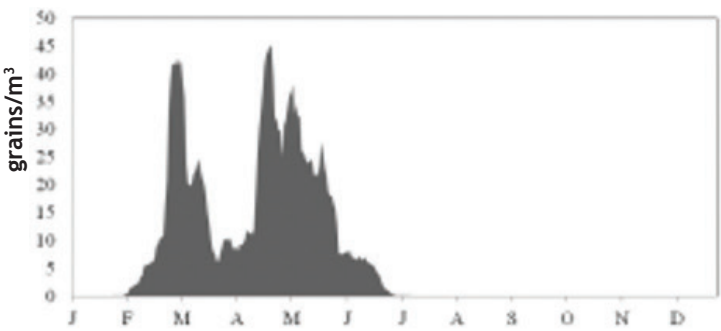

Betulaceae

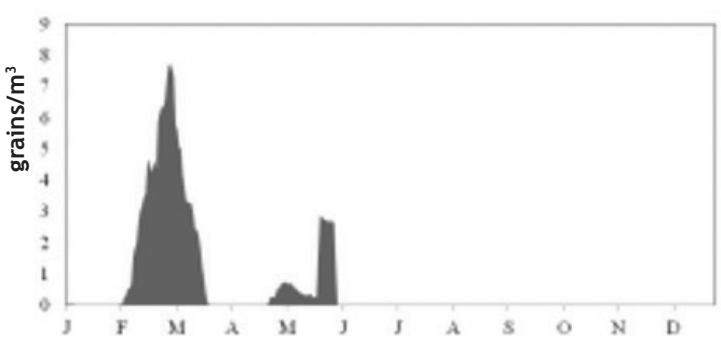

Poeaceae

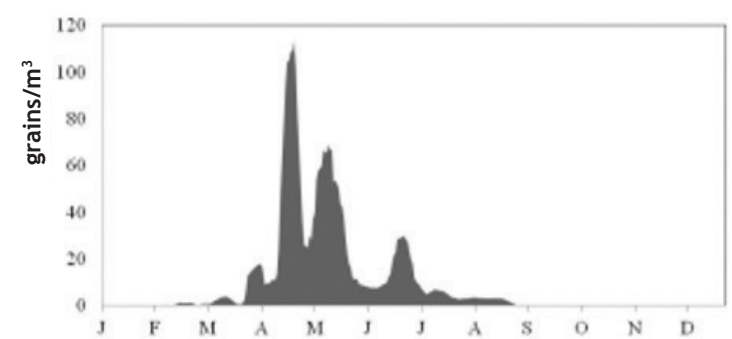

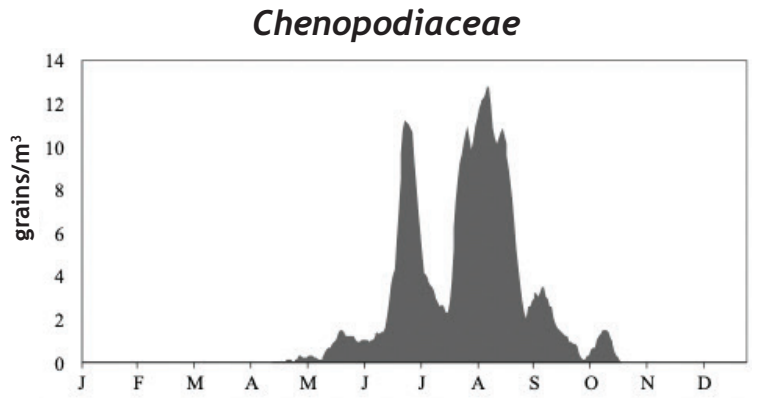
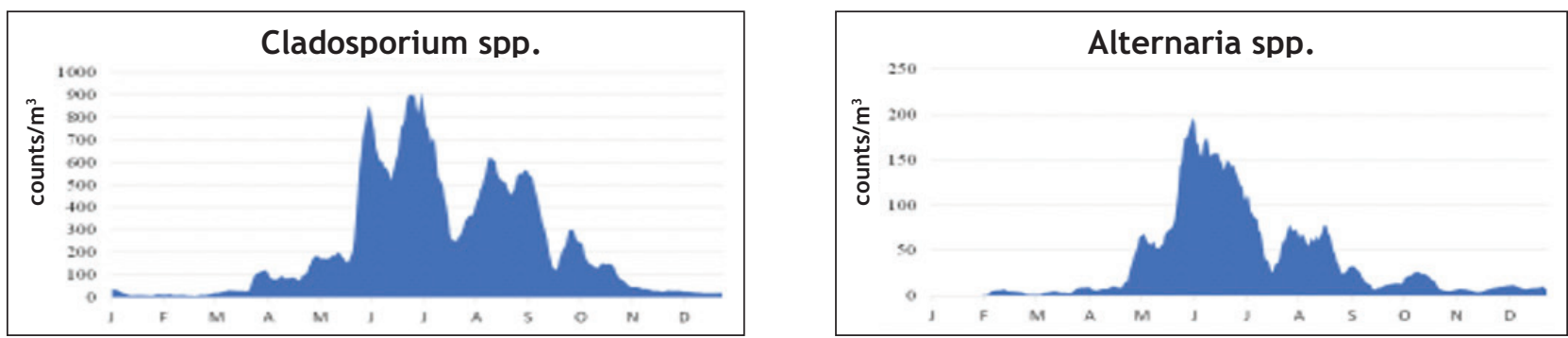

Figure 2 (Continued). 
(C)

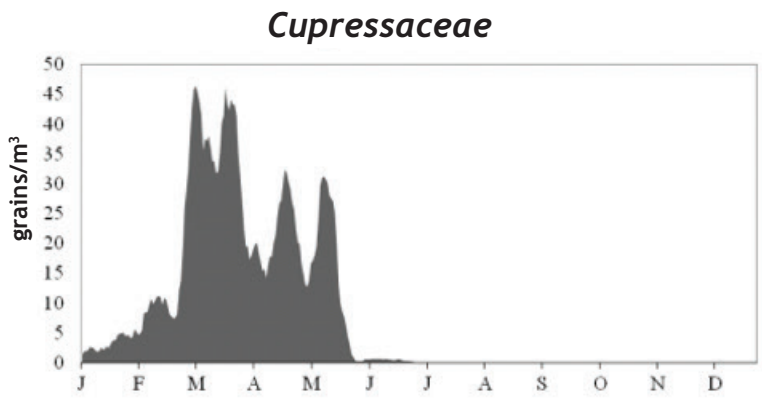

Platanaceae

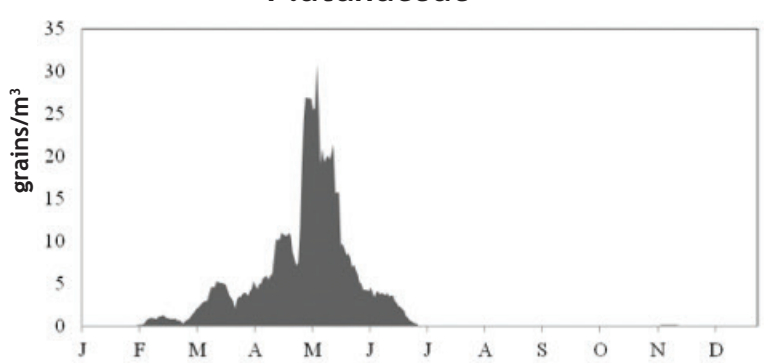

Oleaceae

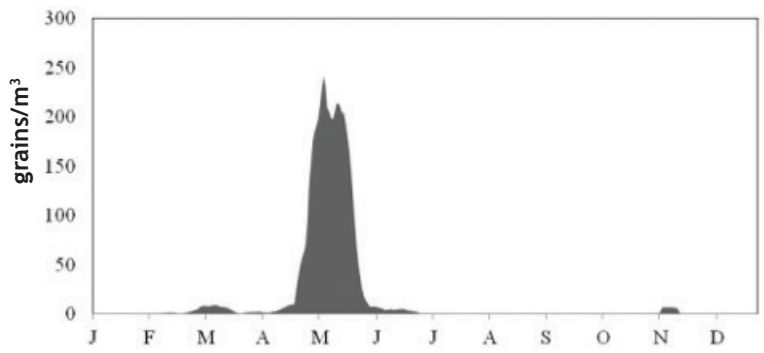

Pinaceae

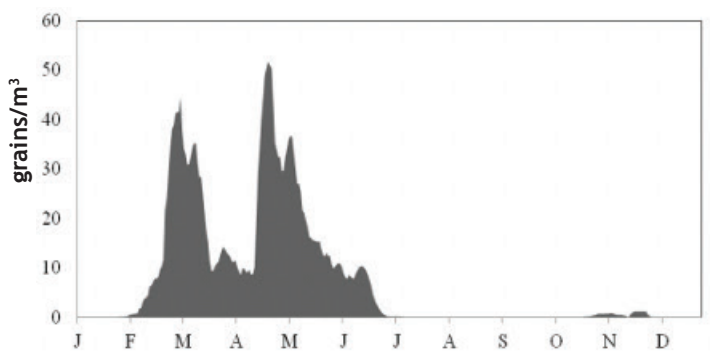

Betulaceae

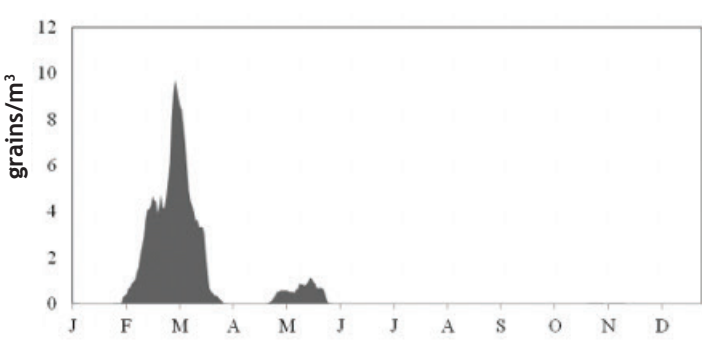

Poeaceae

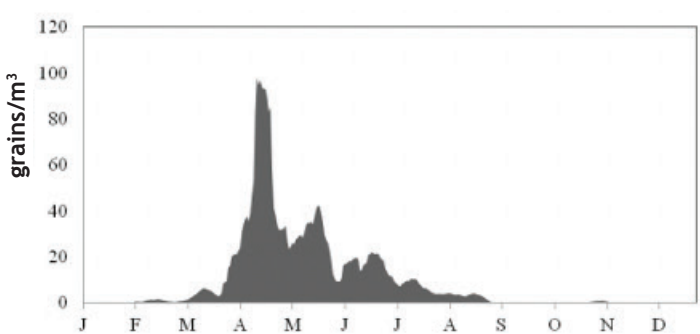

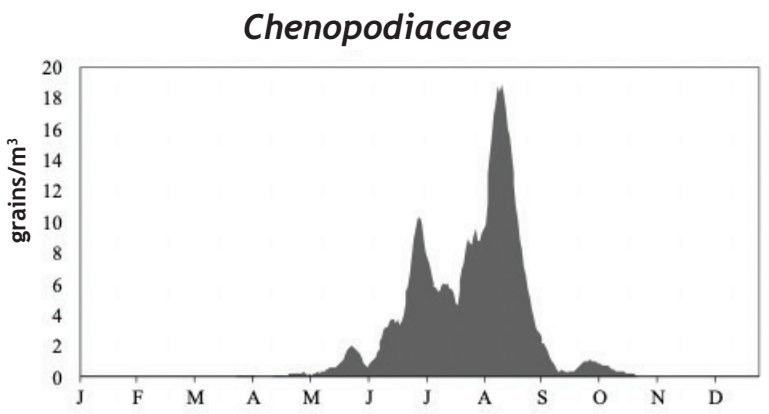
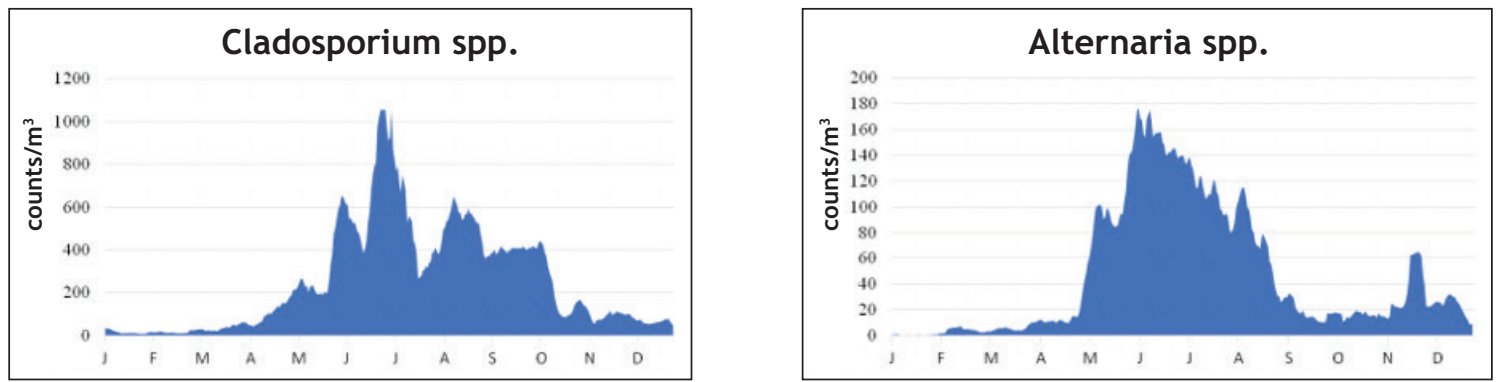

Figure 2 (Continued). 
Table 3 Impact of climatic factors on atmospheric concentration of pollen and fungi. ${ }^{\mathrm{a}}$

\begin{tabular}{llrc}
\hline Pollen and & \multicolumn{3}{c}{$\begin{array}{c}\text { Spearman } \\
\text { correlation }\end{array}$} \\
fungi type & Climatic factor & coefficient & P value \\
\hline Cupressaceae & Rainy days & 0.808 & $0.001^{* *}$ \\
Betulaceae & Relative humidity & 0.623 & $0.03^{*}$ \\
& Rainy days & 0.750 & $0.005^{* *}$ \\
Chenopodiaceae & Mean temperature & 0.968 & $<0.001^{* *}$ \\
& Rainy days & -0.648 & $0.023^{*}$ \\
& Relative humidity & -0.872 & $<0.001^{* *}$ \\
Alternaria & Mean temperature & 0.909 & $<0.001^{* *}$ \\
& Relative humidity & -0.818 & $<0.001^{* *}$ \\
Cladosporium & Mean temperature & 0.930 & $<0.001^{* *}$ \\
& Relative humidity & -0.867 & $<0.001^{* *}$ \\
& Rainy days & -0.622 & 0.031 \\
\hline
\end{tabular}

aResults from single linear regression analysis; only significant associations are shown.

${ }^{*} \mathrm{P}<0.05$.

${ }^{* *} P<0.001$.

spore counts and meteorological parameters, regression analysis revealed a statistically significant positive correlation $(P<0.001)$ of Alternaria with mean daily temperature. On the contrary, the correlation of Alternaria with relative humidity was negative $(\mathrm{P}<0.001)$. Similar results were obtained for Cladosporium; a positive correlation $(\mathrm{P}<0.001)$ was observed with mean daily temperature and a negative correlation $(\mathrm{P}<0.001)$ with relative humidity and rainy days $(P=0.031)$.

\section{Discussion}

We first observed that the studied area has an aerobiological composition that included taxa such as Cupressaceae, Pinaceae, Platanaceae, Betulaceae, Oleaceae, and Poaceae and fungi, such as Alternaria and Cladosporium. Because of the geo-climatic conditions that favor the adaption and flowering of several native plants throughout the years, it comes as no surprise that Oleaceae and Poaceae were the most dominant pollens. The typical airborne spectrum in the Mediterranean zone contains Oleaceae, Cupressaceae, Compositae, Poaceae, and Urticaceae..$^{8,11,30}$ Similarly to the 2013 pollen map, ${ }^{1,10}$ the pollen of Oleacea was the most abundant species amongst the other allergens. We found that the MPS was observed in April-May, with the peak concentrations measured in May. Compared with 2013 data, the pollen season was longer, however, characterized by fewer grains $/ \mathrm{m}^{3}$, with possible clinical significance. Allergen maps conducted in other Mediterranean countries (Spain, Italy, Portugal, and Turkey) confirm the importance of the olive as a highly allergenic factor presenting a similar period of distribution and peak concentration as in our study. ${ }^{35}$ Olea europeae pollen is characterized by high allergenicity, ${ }^{36}$ and its presence is very important for allergy. In our study, its concentration was the highest, far more than the other pollens, because of abundant olive trees in Greece.
Herbaceous plants (Poaceae) are also known to have high allergenic potential as Oleaceae. ${ }^{36}$ Poaceae was the second highly concentrated taxa in the atmosphere during the observation period, with an increased total number of grains $\left(9445.1\right.$ grains $\left./ \mathrm{m}^{3}\right)$ and a shorter pollen season compared with previous years. Our results agree with several studies' findings for allergens in Spain that showed that Poaceae is the primary cause of pollinosis in central Spain and Europe in general. ${ }^{28,31}$ The highest peaks were observed from April to mid-July in Alexandroupolis, and for central Spain, the highest pollen season was in May-June because of different climatic conditions. Remarkably, Poaceae was found to have the longest pollination period both in our region and in other Mediterranean countries, as well.

Cupressaceae, a common ornamental tree found widely during the winter season, constitutes a less allergenic pollen. ${ }^{36}$ Accordingly, in our study, the count of the highest taxa was observed during February-May, with the peak point in March and increased spore concentrations than previous years.

Betulaceae was monitored from February to late May, with peak concentrations in March. We observed a longer pollination period and a significant decrease in the number of pollen grains. Pinaceae, another pollen with high allergenicity, ${ }^{36}$ presented a longer duration and higher concentrations than 2013, whose peak was observed during April. Platanus, a widely known ornamental tree in the Mediterranean basin, was considered the third most common allergen in Spain, with over $30 \%$ of allergy sufferers. ${ }^{37}$ The circulation of this pollen in the studied area showed an allocation of the calendar time with the start date in March and end date in June.

The pollen taxa in this study were detected in the atmosphere of North-Eastern Greece for 255 days (February 9 to October 16), corresponding to approximately $70 \%$ of the calendar year. Pollen circulation was generally low in autumn and the beginning of winter. On the contrary, March to May were the months that posed the highest risk for pollen-induced allergies. Compared with our previous study, ${ }^{2}$ we conclude that pollen maps even in the same area present differences from year to year based on the start of the pollination day, the duration, the peak date, and the total pollen grains in each pollen species. The differences may be because of changes in climate factors or other human forces, such as urban or industrial pollution. These findings emphasize the importance of the pollen calendars for AR control.

Two highly allergenic fungal spores (Cladosporium and Alternaria) were observed throughout the year and in all seasons. Cladosporium was the fungus with the highest spore concentration (180,129.9 average spores/per year) than Alternaria $(28,026.1$ average spores/per year), as it can release billions of spores per day. ${ }^{38}$ Cladosporium was marked in higher concentrations during the 2015-2017 period than in 2013. The highest concentrations were noted from May to September, and two high peaks were observed (one in July and a smaller one in August-November). The dominance of Cladosporium has also been observed in many countries including Australia, Portugal, Spain, Turkey, the United States, and Greece. ${ }^{24,39,40}$ However, there were differences in total counts. ${ }^{41}$ In some European countries, Cladosporium may reach values of 700,000 spores $/ \mathrm{m}^{3}$ per 
year, and Alternaria varies between 20,000 and 30,000 spores $/ \mathrm{m}^{3}$ per year. ${ }^{31}$ The annual presence of both types varied from 70,000 to more than 200,000 spores $/ \mathrm{m}^{3}$ per year in the Iberian Peninsula, ${ }^{42}$ with Cladosporium exceeding in some areas with a level of 300,000 spores $/ \mathrm{m}^{3}$ per year. Higher spore concentrations for Cladosporium can be attributed to region-specific climate conditions and ecology. In our study, both fungi spores were present throughout the year, with Cladosporium being the dominant type. No fungal spore free season was detected. ${ }^{41}$ Alternaria peaked in June and the highest season was recorded during summer (May-August). For Alternaria we found a smaller pollination period and lower concentrations compared with 2013.

Finally, we observed that climate and weather play a dominant role in the seasonal temporal variability of pollen production and spatial distribution and, as a result, contribute to the formation of an atmospheric pattern of pollen dispersal. ${ }^{18,19}$ In the present study, we evaluated the association of pollen grains and fungi spores counts with meteorological parameters and found that rainfall was the most significant parameter for pollen taxa. The analysis of fungal spores revealed a statistically significant positive correlation of both fungi spores with mean daily temperature and a negative correlation with relative humidity. Our results correlated with the outcomes of previous studies from the Mediterranean region. But several differences regarding the duration and the peak of the pollination period may be observed because of climatic factors or environmental pollution.

\section{Conclusion}

In this study, we developed a 3-year pollen map of an area characterized by typical Mediterranean climate and discussed changes in seasonal patterns through the years. It has been shown that continuous pollen monitoring could protect allergic patients from exposure and prophylactic medication, thus reducing the referral to medical centers by $50 \% .{ }^{43}$ Accordingly, evidence on seasonal aeroallergen levels can help generate an alarm system for sensitized individuals and doctors.

\section{References}

1. Fiona L, Cecilia B, David B, Hess J. Pollen calendars and maps of allergic pollen in North America. Aerobiologia. 2019;35:61333. https://dx.doi.org/10.1007/s10453-019-09601-2

2. Nikolaidis C, Katotomichelakis M, Nena E, Makris M, Tsakas M, Michopoulos I, et al. Seasonal variations of allergenic pollen in a Mediterranean region-Alexandroupolis, north-east Greece. Ann Agric Environ Med. 2015;22:685-9. https://dx.doi. org/10.5604/12321966.1185776

3. D’Amato G, Cecchi L, Bonini S, Nunes C, Annesi-Maesano I, Behrendt $\mathrm{H}$, et al. Allergenic pollen and pollen allergy in Europe. Allergy. 2007;62:976-90. https://dx.doi.org/10.1111/j. 1398-9995.2007.01393.x

4. Sibbald B, Strachan D. Epidemiology of rhinitis. In: Busse W, Holgate ST, editors. Mechanisms in asthma and rhinitis: Implications for diagnosis and treatment. Oxford: Blackwell Scientific; 1994. p. 32-43.
5. Raulf M, Buters J, Chapman M, Cecchi L, de Blay F, Doekes G, et al. Monitoring of occupational and environmental aeroallergens-EAACI Position Paper. Concerted action of the EAACI IG Occupational Allergy and Aerobiology \& Air Pollution. Allergy. 2014;69:1280-99. https://dx.doi.org/10.1111/all.12456

6. Cecchi L, D’Amato G, Ayres JG, Galan G, Forastiere F, Forsberg B, et al. Projections of the effects of climate change on allergic asthma: The contribution of aerobiology. Allergy. 2010;65:1073-1081. https://dx.doi.org/10.1111/j. 1398-9995.2010.02423.x

7. Makris M, Koulouris S, Koti I, Aggelides X, Sideri K, Chliva C, et al. Temporal relationship of allergic rhinitis with asthma and other co-morbidities in a Mediterranean country: A retrospective study in a tertiary reference allergy clinic. Allergol Immunopathol. 2010;38:246-53. https://dx.doi.org/10.1016/j. aller.2009.11.007

8. Smith $M$, Jager S, Berger U, Sikoparija B, Hallsdottir $M$, Sauliene I, et al. Geographic and temporal variations in pollen exposure across Europe. Allergy. 2014;69:913-23. https://dx. doi.org/10.1111/all.12419

9. Ribeiro H, Oliveira M, Ribeiro N, Cruz A, Ferreira A, Machado H, et al. Pollen allergenic potential nature of some trees species: A multidisciplinary approach using aerobiological, immunochemical and hospital admissions data. Environ Res. 2009;109:328-33. https://dx.doi.org/10.1016/j.envres.2008. 11.008

10. Katotomichelakis M, Nikolaidis C, Makris M, Zhang N, Aggelides $\mathrm{X}$, Constantinidis TC, et al. The clinical significance of the pollen calendar of the Western Thrace/northeast Greece region in allergic rhinitis. Int Forum Allergy Rhinol. 2015;5:1156-63. https://dx.doi.org/10.1002/alr.21623

11. Canonica GW, Bousquet J, Mullol J, Scadding G., Virchow J. A survey of the burden of allergic rhinitis in Europe. Allergy. 2007;62(Suppl 85):S17-25. https://dx.doi.org/10.1111/j.13989995.2007.01549.x

12. Greiner A, Hellings $P$, Rotiroti G, Scadding G. Allergic rhinitis. Lancet. 2011;378:2112-22. https://dx.doi.org/10.1016/ S0140-6736(11)60130-X

13. Bhattacharyya N. Functional limitations and work-days lost associated with chronic rhinosinusitis and allergic rhinitis. Am J Rhinol Allergy. 2012;26:120-2. https://dx.doi.org/10.2500/ ajra.2012.26.3752

14. Bousquet J, Burney PG, Zuberbier T, Cauwenberge PV, Akdis CA, Bindslev-Jensen C, et al. GA2LEN (Global Allergy and Asthma European Network) addresses the allergy and asthma "epidemic". Allergy. 2009;64:969-77. https://dx.doi. org/10.1111/j.1398-9995.2009.02059.x

15. Sung M, Kim SW, Kim JH, Lim DH. Regional difference of causative pollen in children with allergic rhinitis. J Korean Med Sci. 2017;32:926-32. https://dx.doi.org/10.3346/jkms.2017. 32.6 .926

16. Silverberg J, Braunstein M, Lee-Wong M. Association between climate factors, pollen counts, and childhood hay fever prevalence in the United States. J Allergy Clin Immunol. 2015;135:463-9. https://dx.doi.org/10.1016/j.jaci.2014.08.003

17. de Weger L, Bergmann KC, Rantio-Lehtimäki A, Dahl Å, Buters J, Déchamp C, et al. Impact of pollen. In: Sofiev M, Bergmann KC, editors. Allergenic pollen: A review of the production, release, distribution and health impacts. Dordrecht: Springer; 2013. p. 161-215.

18. D’Amato G, Spieksma F, Liccardi G, Jäger S, Russo $M$, Kontou-Fili K, et al. Pollen-related allergy in Europe. Position Paper of the European Academy of Allergology and Clinical Immunology. Allergy. 1998;53:567-78. https://dx.doi. org/10.1111/j.1398-9995.1998.tb03932.x

19. Damialis A, Gioulekas D, Lazopoulou C, Balafoutis C, Vokou D. Transport of airborne pollen into the city of Thessaloniki: The effects of wind direction, speed and persistence. Int J 
Biometeorol. 2005;49:139-45. https://dx.doi.org/10.1007/ s00484-004-0229-z

20. Gonianakis M, Baritaki M, Neonakis I, Gonianakis I, Kypriotakis Z, Darivianaki E, et al. A 10-year aerobiological study (1994-2003) in the Mediterranean island of Crete, Greece: trees, aerobiologic data, and botanical and clinical correlations. Allergy Asthma Proc. 2006;27:371-7. https://dx. doi.org/10.2500/aap.2006.27.2935

21. Papageorgiou P. Particularities of pollen allergies in Greece. Pediatr Pulmonol. 1999;27(Suppl 18):168-71. https://dx.doi.org/ 10.1002/(SICI)1099-0496(1999)27:18+\%3C168::AID-PPUL55\%3E3. $0 . \mathrm{CO} ; 2-\mathrm{T}$

22. Gioulekas D, Damialis A, Papakosta D, Syrigou A, Mpaka G Saxoni F, et al. 15- Year aeroallergen records. Their usefulness in Athens Olympics. Allergy. 2004;58:933-8. https://dx.doi org/10.1034/j.1398-9995.2003.00244.x

23. Gioulekas D, Papakosta D, Damialis A, Spieksma F, Giouleka P, Patakas D. Allergenic pollen records (15 years) and sensitization in patients with respiratory allergy in Thessaloniki, Greece. Allergy. 2004;59:174-84. https://dx.doi.org/10.1046/ j.1398-9995.2003.00312.x

24. Katotomichelakis M, Nikolaidis C, Makris M, Proimos E, Aggelides $\mathrm{X}$, Constantinidis TC, et al. Alternaria and Cladosporium calendar of Western Thrace: Relationship with allergic rhinitis symptoms. Laryngoscope. 2016;126: E51-56. https://dx.doi.org/10.1002/lary.25594

25. Grant Smith E. Sampling and identifying allergenic pollens and molds. An Illustrated Manual for Physicians and Lab Technicians. San Antonio, TX: Blewstone Press; 1984.

26. Caulton E, Lacey ME, Allitt U, Crosby R, Emberlin J, Hirst J.M. Airborne pollens and spores: A guide to trapping and counting. Rotherham: British Aerobiological Federation; 1995.

27. Rodriguez-de la Cruz D, Sanchez-Reyes E, Davila-Gonzalez I, Lorente-Toleano F, Sanvhez-Sanchez J. Airborne pollen calendar of Salamanca, Spain, 2000-2007. Allergol Immunopathol (Madr). 2010;38:307-12. https://dx.doi.org/10.1016/j.aller.2010.04.001

28. Perez-Badia R, Rapp A, Morales C, Sardinero S, Galan C, Garcia-Mozo H. Pollen spectrum and risk of pollen allergy in central Spain. Ann Agric Environ Med. 2010;17:139-151. Available from: https://pubmed.ncbi.nlm.nih.gov/20684492/

29. Gucel S, Guvensen A, Ozturk M, Celik A. Analysis of airborne pollen fall in Nicosia (Cyprus). Environ Monit Assess. 2013;185:157-69. https://dx.doi.org/10.1007/s10661-012-2540-1

30. Bousquet J, Cour P, Guerin B, Michel F. Allergy in the Mediterraneanarea.I. Pollencounts and pollinosis of Montpellier. Clin Allergy. 1984;14:249-58. https://dx.doi.org/10.1111/j. 1365-2222.1984.tb02204.x

31. Spieksma F. Regional European pollen calendars. In: D’Amato G, Spieksma FT, Bonini S, editors. Allergenic pollen and pollinosis in Europe. London: Blackwell Scientific Publications; 1991, p. 49-65.
32. Emberlin J, Mullins J, Corden J, Jones S, Millington W, Brooke $M$, et al. Regional variations in grass pollen seasons in the UK, long- term trends and forecast models. Clin Exp Allergy. 1999;29:347-56. https://dx.doi.org/10.1046/ j.1365-2222.1999.00369.x

33. Oh J, Lee H, Kang I, Kim S-W, Park K-S, Kook M-H, et al. The revised edition of Korean calendar for allergenic pollens. Allergy Asthma Immunol Res. 2012;4:5-11. https://dx.doi. org/10.4168/aair.2012.4.1.5

34. Kosisky S, Marks M, Nelson M. Pollen aeroallergens in the Washington, DC, metropolitan area: A 10-year volumetric survey (1998-2007). Ann Allergy Asthma Immunol. 2010;104:22335. https://dx.doi.org/10.1016/j.anai.2010.01.005

35. Hoffmann T, Şahin A, Aggelidis X, Arasi S, Barbalace A, Bourgoin A, et al. "Whole" vs. "fragmented" approach to EAACI pollen season definitions: A multicenter study in six Southern European cities. Allergy. 2020;75:1659-71. https://dx.doi.org/ 10.1111/all.14153

36. Grant-Smith E. Sampling and identifying allergenic pollens and molds. San Antonio, TX: Blewstone Press; 1990.

37. Rojo J, Rapp A, Lara B, Sabariego S, Fernández-González F, Pérez-Badia R. Characterization of the airborne pollen spectrum in Guadalajara (central Spain) and estimation of the potential allergy risk. Environ Monit Assess. 2016;188:130. https://dx.doi.org/10.1007/s10661-016-5129-2

38. Reyes E, de la Cruz D, Merino M, Sanchez J. Meteorological and agricultural effects on airborne Alternaria and Cladosporium spores and clinical aspects in Valladolid (Spain). Ann Agric Environ Med 2009;16:53-61. Available from: https://pubmed. ncbi.nlm.nih.gov/19572478/

39. Erkara I, Asan A, Yilmaz V, Pehlivan S, Okten S. Airborne Alternaria and Cladosporium species and relationship with meteorological conditions in Eskisehir City, Turkey. Environ Monit Assess 2008;144:31-41. https://dx.doi.org/10.1007/s10661-007-9939-0

40. Katial R, Zhang $Y$, Jones R, Dyer P. Atmospheric mold spore counts in relation to meteorological parameters. Int $\mathrm{J}$ Biometeorol. 1997;41:17-21. https://dx.doi.org/10.1007/s004840050048

41. Oliveira $M$, Ribeiro $H$, Abreu I. Annual variation of fungal spores in atmosphere of Porto: 2003. Ann Agric Environ Med. 2005;12:309-15. Available from: https://pubmed.ncbi.nlm.nih. gov/16457491/

42. Sabariego S, Diaz de la Guardia C, Alba F. [Aerobiological study of Alternaria and Cladosporium conidia in the atmosphere of Almeria (SE Spain)]. Rev Iberoam Micol. 2004;21:121-27. Spanish. Available from: https://pubmed.ncbi.nlm.nih.gov/15709785/

43. Douladiris N, Savvatianos S, Roumpedaki I, Skevaki C, Mitsias D, Papadopoulos N. A molecular diagnostic algorithm to guide pollen immunotherapy in southern Europe: towards component-resolved management of allergic diseases. Int Arch Allergy Immunol. 2013;162:163-72. https://dx.doi.org/10. $1159 / 000353113$ 